\title{
VIOLÊNCIA DE GÊNERO: O QUE DIZEM AS JOVENS MULHERES DA EDUCAÇÃO DE JOVENS E ADULTOS NO ALTO SERTÃO DA BAHIA
}

\section{Maria de Fátima Pereira Carvalho' \\ Carmem Lúcia Eiterer ${ }^{2}$}

Resumo: Este artigo discute o tema da violência de gênero vivida por jovens mulheres inseridas na Educação de Jovens e Adultos (EJA), no Alto Sertão da Bahia. Trata-se de um recorte dos dados produzidos no contexto de uma pesquisa qualitativa em que se realizou Grupos de Discussão e entrevistas semiestruturadas personalizadas com concluintes da segunda etapa do Ensino Fundamental na rede pública de ensino de Guanambi/BA. Os resultados do estudo apontam que as jovens mulheres da EJA não são quaisquer mulheres, mas sim jovens, mulheres, pobres, em sua maioria negras e nordestinas, que vivenciam enfrentamentos para permanecer no processo de escolarização.

Palavras-chave: Educação de jovens e adultos; gênero; violência.

Abstract: This article discusses the issue of gender-based violence experienced by young women in adult and youth education program (EJA) in the Alto Sertão of Bahia. It is a cutout of the data produced in the context of a qualitative research; we conducted discussion groups and personalized semi-structured interviews with graduates of the 2 nd stage of elementary school in the public school system of Guanambi-BA. The results of the study indicate that the young women of EJA are not any women; they are young, poor, mostly black, from the Northeast region of Brazil, who experience confrontations to remain in the schooling process.

Keywords: Adult and youth education; gender; violence.

\section{Introdução}

Este texto apresenta um recorte da pesquisa de doutorado Jovens mulheres da Educação de Jovens e Adultos (EJA) e a constituição de seus projetos de vida,

Doutoranda em Educação, Universidade Federal de Minas Gerais, Brasil. E-mail: f13carvalho@hotmail.com. Orcid: 0000-0003-2273-4809

2 Doutora em Educação, Universidade Federal de Minas Gerais, Brasil. E-mail: eiterercarmem@gmail.com. Orcid: 0000-0002-6978-155X 
desenvolvida com jovens mulheres inseridas na Educação de Jovens e Adultos (EJA), no Alto Sertão da Bahia. Ele situa-se no entrelaçamento de gênero, juventude e violência, mais especificamente no campo da violência de gênero, e parte do olhar das participantes da pesquisa.

Do ponto de vista metodológico, trata-se de uma pesquisa qualitativa, devido às características das questões e dos objetivos que norteiam o processo de investigação. No estudo realizado, o contexto social foi composto por escolas da rede municipal de ensino de Guanambi/BA que atendem a EJA. Para a produção dos dados, foram utilizados cinco grupos de discussão (um em cada escola), dos quais participaram de cinco a doze jovens mulheres concluintes da segunda etapa do Ensino Fundamental ${ }^{3}$ na EJA da rede pública de ensino de Guanambi, no período de 2017 a 2019. Para a escrita deste texto, foram selecionados aqueles depoimentos cujas discussões e reflexões se aproximam dos objetivos do tema recortado.

Ao analisar o cenário vivenciado pelas jovens mulheres da EJA do Alto Sertão da Bahia, é possível assegurar que elas não são quaisquer mulheres. Elas são jovens, mulheres, pobres, em sua maioria negras, nordestinas, sertanejas, e vivenciam muitos enfrentamentos para viver o processo de escolarização e persistir nele.

\section{Metodologia}

Quanto à escolha das participantes da pesquisa, inicialmente realizamos um levantamento da população jovem, adulta e/ou idosa matriculada no mencionado município, analisando os perfis dos(as) educandos(as), com vistas a identificar jovens que contemplassem a diversidade de trajetórias presentes no campo da EJA (consideramos idade, gênero, raça, cor, trabaIho, local de moradia etc.). De posse desses dados, efetuamos um levantamento da população de jovens mulheres inseridas na referida modalidade de ensino no município, a fim de recolher informações que subsidiassem a localização das jovens para a formação dos Grupos de Discussão (GD).

A seleção das jovens se deu por adesão após a apresentação da proposta de pesquisa nas salas de aula das escolas. Assim sendo, foram inclusas jovens mulheres negras, porque essa é uma característica acentuada no campo da EJA; além disso, procuramos contemplar participantes provindas tanto do

$3 \bigcirc$ Ensino Fundamental organiza-se em duas etapas: I, de $1^{\circ}$ a $5^{\circ}$ ano; e ll, de $6^{\circ}$ a $9^{\circ}$ ano. 
meio rural quanto do âmbito urbano. Participaram do estudo 51 educandas da EJA do munícipio de Guanambi, Alto Sertão da Bahia.

Para a coleta dos dados, utilizou-se a técnica de GD. Estes foram realizados nas escolas que atendem a EJA, de acordo com o turno de estudo das participantes. A análise das informações foi fundamentada na metodologia de análise de conteúdo de Bardin (1977).

\section{Jovens mulheres da EJA}

Quem são as jovens mulheres inseridas na EJA, em particular no segundo segmento do Ensino Fundamental? São mulheres pertencentes a várias categorias de classe, religião, raça, etnia, gênero, território e geração. São diferentes entre si: há jovens mulheres que se declaram afrodescendentes e outras que se reconhecem como pardas; umas são católicas, outras, evangélicas e há aquelas que não praticam nenhuma religião; a maioria delas trabalha no mercado informal, em ocupações laborais não especializadas, mais especificamente nos cargos de doméstica e/ou babá. A tabela que segue apresenta a cor e o estado civil $^{4}$ das participantes dos GD.

Tabela 1: Cor e estado civil das participantes da pesquisa

\begin{tabular}{|c|c|c|c|c|c|c|c|c|c|}
\hline \multirow{2}{*}{ GD } & \multicolumn{4}{|c|}{ Cor } & \multirow{2}{*}{ Total } & \multicolumn{3}{|c|}{ Estado civil } & \multirow{2}{*}{ Total } \\
\hline & Branca & Morena & Parda & Preta & & Amasiada & Casada & Solteira & \\
\hline GD 1 & 1 & 2 & 4 & 2 & 9 & 3 & 1 & 5 & 9 \\
\hline GD 2 & - & 3 & 9 & - & 12 & - & 4 & 8 & 12 \\
\hline GD 3 & - & 3 & 9 & & 12 & 1 & 3 & 8 & 12 \\
\hline GD 4 & 2 & 6 & 4 & 1 & 13 & 5 & 1 & 7 & 13 \\
\hline GD 5 & - & 2 & 3 & - & 5 & - & - & 5 & 5 \\
\hline Total & 3 & 16 & 29 & 3 & 51 & 9 & 9 & 33 & 51 \\
\hline
\end{tabular}

Fonte: Elaboração própria.

Embora o número de participantes presentes nos GD seja elevado, a participação e o envolvimento das jovens mulheres nos debates variaram em uma média de três a seis jovens por grupo; as demais pouco ou nada falavam durante as discussões. A quantidade total de 51 jovens se deu pela maneira como foi feita nossa inserção nas escolas e, mais especificamente, como nos aproximamos das jovens mulheres inseridas na EJA. Alguns grupos

4 Para o estado civil, seguimos as categorias apresentadas no discurso delas. Estas foram: amasiada, solteira e casada. Observamos que, mesmo coabitando com o parceiro, algumas se definem solteiras, enquanto outras optam por amasiadas. 
ultrapassam o número de participantes nos GD sugerido por alguns autores ${ }^{5}$, o que, a nosso ver, não prejudicou o andamento das conversas.

Observamos que quase todas as jovens mulheres participantes da pesquisa são negras; ou seja, das 51 participantes dos cinco GD, 48 se autodeclaram morenas, pardas e/ou pretas (negras), sendo apenas três brancas, realidade comum às turmas da EJA no país. Dessas jovens, a maioria declara que é solteira; algumas são casadas, outras, amasiadas. Apesar de coabitarem com seus companheiros, muitas se declaram solteiras e não amasiadas.

\section{Jovens mulheres e relação de gênero}

$\bigcirc$ campo de estudos acerca das questões de gênero tem enveredado por diferentes concepções, instituídas a partir de diversas posições teórico-epistemológicas, políticas e ideológicas ao longo dos anos. Silva (2017, p. 71), embora a literatura de gênero aborde as mulheres em geral e as mudanças ocorridas quando elas começaram a sair do espaço privado e a ingressar no público, ressalta que "esta não é a experiência de parte das mulheres negras brasileiras, que também já estavam no espaço público como domésticas, vendedoras ambulantes, quituteiras e cozinheiras".

Segundo Narvaz, Sant'Anna e Tesseler (2013), das concepções biologistas às culturalistas e pós-estruturalistas, na contemporaneidade, gênero remete ao paradoxo entre igualdade e diferença não somente entre homens e mulheres, mas também entre homens e entre mulheres. Essas perspectivas articulam-se a diversas outras marcações da diferença, como classe social, etnia, raça, geração, religiosidade e sexualidade.

Tratando de mulheres nordestinas, Reis (2014, p. 127) afirma que "as relações de gênero não podem ser entendidas como fato isolado na sociedade, pelo contrário, [...] pois o modelo paradigmático de ser homem e ser mulher regula todas as nossas atividades". A autora exemplifica esse processo a partir de depoimentos de mulheres que falam das tentativas dos maridos de impedi-las de participar de atividades na Igreja e nos movimentos sociais, das responsabilidades com a vida doméstica para poupar os homens dos problemas presentes no cotidiano familiar e das funções que desempenham como mães e trabalhadoras ao lado dos maridos, apesar de sua força de trabalho não ser reconhecida como geradora de renda (REIS, 2014).

5 Sugere-se que o tamanho do grupo varie entre cinco e dez participantes. 
Enquanto proposta de um sistema de classificação, a "categoria" gênero, em sua forma mais difusa e difundida, tem sido acionada quase sempre de forma binária (raramente em formato também tripartite) para se referir à lógica das diferenças entre: feminino e masculino, homens e mulheres e, também, entre a homo e a heterossexualidade, penetrando já aí neste segundo eixo fundamental deste novo campo que é a fronteira da sexualidade. (MATOS, 2008, p. 336).

Como também destaca Matos (2008), o pensamento feminista não se constitui como um corpus unificado de conhecimento. Sabemos igualmente que o construto gênero foi apropriado das formas mais distintas pelas inúmeras áreas disciplinares e suas teorias. Porém, é importante destacar que, sendo essa aproximação mais superficial ou mais substantiva, todos derivam de um ponto comum - a assimetria de poder na subordinação da mulher ao homem - para entender e explicitar, em termos relacionais, as vicissitudes do patriarcado e o modo como tais relações de dominação e opressão são elaboradas socialmente. Barbosa (2013, p. 32) aponta que "o conceito também abriu espaço analítico para se questionar as próprias categorias de homem e de masculino, bem como de mulher e de feminino, que passaram a ser fruto de intenso processo de desconstrução".

Neste trabalho, gênero será abordado na perspectiva das especificidades das jovens mulheres inseridas na EJA. Isso porque

gênero é constituído e representado de maneira diferente segundo nossa localização dentro de relações globais de poder. Nossa inserção nessas relações globais de poder se realiza através de uma miríade de processos econômicos, políticos e ideológicos [...] Dentro dessas estruturas de relações sociais não existimos simplesmente como mulheres, mas como categorias diferenciadas, tais como "mulheres da classe trabalhadora", "mulheres camponesas" ou "mulheres imigrantes". Cada descrição está referida a uma condição social específica. Vidas reais são forjadas a partir de articulações complexas dessas dimensões. (BRAH, 2006, p. 341).

Segundo essa mesma autora, o signo "mulher" tem sua própria especificidade constituída dentro e através de configurações historicamente específicas de relações de gênero. "Seu fluxo semiótico assume significados específicos em discursos de diferentes 'feminilidades' onde vem a simbolizar trajetórias, circunstâncias materiais e experiências culturais históricas particulares" (BRAH, 2006, p. 341).

Nessa direção, conforme Paula de Almeida Silva (2018, p. 47), 
ser mulher no ocidente significa faltas e qualidades intrinsecamente femininas, que, se não são apresentadas em um corpo feminino, este corpo será considerado fora da curva e descartado, pois não pode pertencer à história das mulheres. A história oficial e enviesada, contada a partir de uma visão patriarcal, heteronormativa, caucasiana, masculina e europeia, retira dos autos da história a resistência das mulheres a um sistema capaz de dizer que elas não poderiam fazer parte simplesmente por serem mulheres.

Em se tratando dos países latino-americanos, a quantas mulheres não é negada diariamente a possibilidade de assumir papéis que historicamente são destinados aos homens para que fiquem com a sensação de que não são capazes de assumir tais funções? As diferentes construções de gênero podem ser pensadas quando compreendemos que não há, por exemplo, a mulher enquanto representação de uma essência inerente a todas as mulheres. As "mulheres" também são seres reais, históricos e sociais, definidos pelas tecnologias de gênero e "engendrados" nas relações sociais (LAURENTIS apud ARAÚJO, 2009, p. 120).

Leoncy (2013, p. 27) afirma que "no Brasil contemporâneo, as mulheres figuram como sujeitos de direitos e relevância social, assumindo econômica e socialmente sua importância numa sociedade que historicamente as relegava a segundo plano". Para a autora, embora as mulheres tenham alcançado conquistas significativas ao longo dos anos, elas ainda experimentam uma situação de maior vulnerabilidade e desvalorização que os homens. Isso se deve a ainda pesarem, sobre elas, as restrições advindas das responsabilidades reprodutivas, ou seja, toda a carga das tarefas relativas ao cuidado da casa e dos filhos, o que, muitas vezes, dificulta sua inserção e permanência no mercado de trabalho, fator que é especialmente significativo no caso das mulheres mais pobres.

Pensar as jovens mulheres na EJA e suas trajetórias de vida é um terreno ainda pouco explorado. Do ponto de vista da educação das mulheres,

para que a educação básica se torne equitativa, é mister oferecer a todas as crianças, jovens e adultos a oportunidade de alcançar e manter um padrão mínimo de qualidade da aprendizagem. A prioridade mais urgente é melhorar a qualidade e garantir - acesso à educação para meninas e mulheres, e superar todos os obstáculos que impedem sua participação ativa no processo educativo [sic.]. Os preconceitos e estereótipos de qualquer natureza devem ser eliminados da educação. (UNESCO, 1990).

Já Barbosa (2013) aponta que as mudanças econômicas e culturais têm levado ao crescimento da participação das mulheres nos programas da 
Educação de Jovens e Adultos, em uma tentativa de superar a exclusão das mulheres no sistema educacional. "Através da EJA, muitas mulheres estão tendo a oportunidade de iniciar ou dar continuidade a sua escolarização" (BARBOSA, 2013, p. 36). A autora sinaliza, igualmente, que a conquista de novos espaços e a participação da mulher no mundo de trabalho é cada vez maior, "ainda que saibamos que a inserção da mulher na população economicamente ativa e a sua ascensão educacional nas últimas décadas não vieram acompanhadas de condições igualitárias" (BARBOSA, 2013, p. 36).

Então, o que dizer das jovens mulheres cujas trajetórias são interpeladas por gravidez precoce, trabalho doméstico, trabalho no campo, machismo, violência e outros aspectos sociais estigmatizantes? Numa sociedade que quer regular seus corpos a partir de modelos estéticos eurocêntricos e padrões de beleza inatingíveis, quais são seus conflitos e seus dramas? Como esses conflitos interrogam a educação escolar?

No campo da EJA, fatores ligados ao gênero têm interferido na participação na escola, conforme ressaltam Narvaz, Sant'Anna e Tesseler (2013, p. 100): "a necessidade de arcar com as responsabilidades familiares advindas do casamento e a maternidade é um dos principais motivos de evasão das mulheres adultas da escola, sobretudo se forem pobres, negras e habitantes das áreas rurais". Entretanto, pesquisas como as de Ferreira (2007) e Menezes (2005) também apontam que a escolarização tem contribuído positivamente para a redefinição da imagem que essas mulheres têm de si e de seu grupo de pertença, favorecendo o desenvolvimento de sua autonomia e sua permanência na escola.

Narvaz, Sant'Anna e Tesseler (2013), ao pesquisarem os motivos para o retorno à escola na modalidade da EJA, evidenciam diferentes perspectivas. $\bigcirc$ desejo de concluir os estudos para o sexo masculino está "associado à expectativa de melhor colocação e melhor remuneração no mercado de trabalho" (NARVAZ; SANT'ANNA; TESSELER, 2013, p. 101). Já para as mulheres, o retorno aos estudos está ligado ao "auxilio e melhor acompanhamento dos filhos e filhas na escola" (NARVAZ; SANT'ANNA; TESSELER, 2013, p. 101).

Souza (2015) destaca o aumento da presença das mulheres nos contextos escolares, inclusive na EJA e analisa como alunas da EJA enxergam sua escolarização. Buscando conhecer suas expectativas e seus desejos, os resultados evidenciam que a grande maioria das alunas deseja dar continuidade aos estudos e pensa até mesmo em ingressar no Ensino Superior. Além disso, 
a pesquisa aponta que, apesar de estarem mais confiantes, as alunas não percebem as tensões geradas pelas relações de gênero, que em muito influenciaram e ainda influenciam seus processos de escolarização (SOUZA, 2015). Tendo em vista a necessidade de assumir responsabilidades advindas do casamento, da maternidade, do trabalho, entre outras, as mulheres se submetem a condições desiguais atribuídas histórica e estreitamente a uma natureza feminina. Para Barbosa (2013, p. 113), "essas mulheres, ao naturalizar tais desafios sob suas perspectivas pessoais, não percebem que são desafios comuns postos a elas enquanto mulheres, em alguns casos, pobres, negras ou pardas".

Nesse contexto, pensar as jovens mulheres que frequentam a EJA no Alto Sertão da Bahia é entrar num terreno não muito explorado, se concebermos esses sujeitos de forma não homogênea, "não como alunas", mas como pessoas que têm sonhos singulares e histórias, trajetórias e projetos de vida. Tratar das experiências, narrativas e planos de jovens mulheres da EJA, na perspectiva dos estudos de gênero, é buscar estudá-las compreendendo o caráter relacional do conceito de gênero, que "tanto é substituto para mulheres como é igualmente utilizado para sugerir que a informação sobre $o$ assunto mulheres é necessariamente informação sobre os homens, que um implica o estudo do outro" (SCOTT, 1995, p. 7).

Pesquisar os projetos de vida de jovens mulheres que frequentam a EJA, verificando em que medida a escolarização toma parte deles, é também pesquisar como eles são constituídos e como as relações de gênero encontram-se postas nessa conjuntura. Os estudos realizados com jovens mulheres no Brasil mostram que a maioria delas enfrenta inúmeros desafios para lidar com o ser jovem, mulher e, ao mesmo tempo, estudante do referido segmento de ensino.

Em nosso estudo, percebemos proibições, relações desiguais de poder, discriminações, exclusões, ausências, obstáculos, limites, tabus, preconceitos e outros problemas relacionados às jovens mulheres da EJA que, a nosso ver, colonizam o pensamento de muitas delas, dificultando outras formas de ser, de existir e de agir diante das condições que lhes são destinadas. Muitas mulheres enfrentam situações de riscos e vulnerabilidade para construir independência financeira, liberdade de pensamento e de escolha. Concordamos com Paula de Almeida Silva (2018, p. 48) quando afirma que em uma "clivagem com raça e classe, mulheres que não são brancas, pertencentes à raça forjada como o modelo de ser humano a ser seguido, enfrentam dificuldades de ordens diferentes às de uma mulher branca com 
vida financeira bem arranjada". No entanto, compreendemos também que "todas as mulheres são vulneráveis à violência de gênero e, de acordo com as intersecções de raça, classe e gênero, essas vulnerabilidades se apresentam de maneiras diferentes" (SILVA, P. A., 2018, p. 48).

\title{
As jovens mulheres e a violência
}

Neste texto, entendemos como violência de gênero tudo aquilo que nos faz sentir inferior aos homens. Paula de Almeida Silva (2018, p. 78), em pesquisa realizada com mulheres jovens na cidade de Goiânia, destaca que a violência de gênero "é uma marcação daquilo que nosso gênero está impedido de ser". Para a pesquisadora, a violência se dá "porque repete a todo momento que estamos interditadas nesta sociedade, que estamos fadadas sempre a nos sujeitarmos às condições impostas ao nosso gênero, que não importa o que façamos, somos apenas mulheres" (SILVA, P. A., 2018, p. 79, grifo da autora).

Nessa mesma direção, Sérgio Gomes da Silva (2010, p. 560, grifo do autor) compreende que

\begin{abstract}
violência que a mulher sofre está no seu dia a dia, incorporada e enraizada no imaginário social coletivo da nossa sociedade, de homens, mas também de mulheres, que legitimam a subordinação do sujeito feminino ao domínio do poder masculino. A violência contra as mulheres está velada no mascaramento e na subordinação da nossa linguagem cotidiana, no uso de expressões e de diversos jogos de linguagem, nas palavras de duplo sentido, na criação de referenciais para dar conta de uma realidade que não é a mais condizente com o seu papel na sociedade, também na criação de estereótipos que moldam formas singulares de preconceito e discriminação através de personagens da vida cotidiana, tais como a doméstica, a dona de casa, a professorinha, a mãe e a garota de programa estilo exportação, entre tantos outros tipos, cuja imagem se transformou em um objeto tão vendável quanto qualquer outro produto de consumo, com o corpo explorado através da mídia, além de servir às leis imperativas do comércio e do turismo sexual.
\end{abstract}

As jovens mulheres inseridas na EJA apontam as diversas situações a que estão expostas em conjunturas de agressão física. Enfatizam as dificuldades enfrentadas por elas cotidianamente:

A violência está muito presente em nosso contexto. Muitas mulheres assassinadas, espancadas. Às vezes, a mulher é morta porque ela não permite viver a situação de um casamento 
já acabado, e o homem não permite que ela diz não ao casamento elou sim à separação. (Participante do GD 2).

\section{Para essas jovens, as mulheres passam por certas experiências que os homens não enfrentam:}

Se fosse para escolhermos entre ser homem e ser mulher, escolheria ser homem, por muitos motivos. Primeiro que a vida do homem é bem mais fácil. A mulher corre o risco de ser estuprada, e o homem não; a mulher corre outros riscos que o homem não corre. É muito raro também você ouvir um caso de homem ser espancado por mulheres por conta da relação. Na maioria das vezes, as mulheres entram num relacionamento e não sabem se vão sair com vida ou não. (Participante do GD 2).

\section{Os depoimentos enfatizam a prevalência do medo. Para ilustrar essa ideia, durante o primeiro encontro do GD 3, em março de 2019, uma das participantes relatou uma situação em que foi vítima, tendo, sem sucesso, buscado a polícia:}

Aconteceu comigo e o meu ex-namorado. O meu ex-namorado me bateu, e a gente saiu nos tapas. No outro dia, eu dei parte dele, mas a policia nem atrás dele foi; e, até hoje, a justiça não resolveu nada. Então tentei eu mesma fazer justiça, enquanto ele dormia, esquentei um copo de água e joguei nas pernas dele, que ficaram todas despeladas. Depois disso, nunca mais falou comigo. Hoje, moro com a minha mãe. Por isso que eu não "amigo" com homem nenhum, não dou certo com homem nenhum, porque, se ele for triscar um dedo em mim, eu faço pior com ele. Eu não vou lutar com ele fisicamente, pois ele é homem, o homem tem muita força, mais força que a mulher... se eu for lutar eu apanho, então eu pego ele dormindo. Uma mulher não aguenta a força e um homem não. (Participante do GD 3).

\section{De acordo com as participantes da pesquisa, mesmo que a relação entre o casal não esteja bem, a mulher não se desliga por medo. Para exemplificar essa situação, uma delas relata:}

Aqui mesmo, em nosso Distrito, não faz muito tempo, uma professora, ex-professora nossa, foi agredida a golpes de arma branca até a morte... Ela ficou impossibilitada de defesa. Eo homem? Ele sumiu. E, até hoje, nada foi feito contra ele; a justiça não fez nada. O que se comentam na rua que foi tudo por ciúmes, porque ela colocou fim no relacionamento de dez anos com ele. Na época, ela havia denunciado o companheiro à polícia. Quando aconteceu essa tragédia, havia um mês que ela estava separada dele. Nada justifica um homem tirar a vida de uma mulher ou vice-versa. (Participante do GD 5). 
Ao mesmo tempo que as jovens mulheres da EJA reconhecem a existência de seus direitos perante a legislação brasileira, elas denunciam as lacunas existentes no cumprimento deles. Uma delas disse: "nós temos proteções como a Lei Maria da Penha ${ }^{6}$, por exemplo, mas muitas mulheres não denunciam por medo, medo de morrer depois que o companheiro sai da cadeia. Elas são ameaçadas" (Participante do GD 4). Vale ressaltar que, com a aprovação da Lei Maria da Penha, "a questão da violência contra a mulher passou a ser encarada não mais como problema particular, mas dentro de uma agenda pública, como um crime a ser combatido, fruto do machismo existente em nossa sociedade" (AGUIAR, 2017, p. 45).

No cotidiano das jovens entrevistadas, em sua maioria negras e residentes em regiões periféricas, a violência tem sido naturalizada e a dependência financeira, somada à falta de recursos para lidar com a dependência psicológica, resulta, muitas vezes, no silenciamento e no medo da denúncia. Como elas mesmas asseguram, a Lei Maria da Penha, implementada em 2006, infelizmente não tem garantido a segurança dessas mulheres, que temem ser mortas por seus parceiros, mas, sem alternativas, permanecem em situações de risco.

Atlas da Violência indica que houve um crescimento dos homicidios femininos no Brasil em 2017, com cerca de treze assassinatos por dia. Ao todo, 4.936 mulheres foram mortas, o maior número registrado desde 2007. Entre 2007 e 2017, houve aumento de 20,7\% na taxa nacional de homicídios de mulheres, quando esta passou de 3,9 para 4,7 mulheres assassinadas por grupo de 100 mil mulheres (CERQUEIRA; BUENO, 2019).

Enquanto a taxa de homicídios de mulheres não negras teve crescimento de 4,5\% entre 2007 e 2017, a taxa de homicídios de mulheres negras cresceu $29,9 \%$. Em números absolutos, a diferença é ainda mais brutal, já que, entre as não negras, o crescimento é de 1,7\% e, entre as mulheres negras, é de 60,5\%. Considerando apenas o último ano disponível, a taxa de homicídios de mulheres não negras foi de 3,2 a cada 100 mil mulheres não negras, ao passo que, entre as mulheres negras, a taxa foi de 5,6 para cada 100 mil mulheres neste grupo. A desigualdade racial pode ser vista também quando verificamos a proporção de mulheres negras entre as vitimas da violência letal: $66 \%$ de todas as mulheres assassinadas no país

\footnotetext{
6 A Lei Maria da Penha, Lei n¹1.340, de 7 de agosto de 2006, além de definir e tipificar as formas de violência contra as mulheres (física, psicológica, sexual, patrimonial e moral), prevê a criação de serviços especializados, como os que integram a Rede de Enfrentamento à Violência contra a Mulher, compostos por instituições de segurança pública, justiça e saúde, e da assistência social. Entre as medidas previstas para o atendimento policial às mulheres em situação de violência, a Lei determina a criação, no âmbito da polícia civil, de delegacias especializadas e de equipes capacitadas para a investigação e o atendimento para esse tipo de violência (BRASIL, 2006).
} 
em 2017. $\bigcirc$ crescimento muito superior da violência letal entre mulheres negras, em comparação com as não negras, evidencia a enorme dificuldade que o Estado brasileiro tem de garantir a universalidade de suas políticas públicas (CERQUEIRA; BUENO, 2019).

As jovens mulheres do Alto Sertão da Bahia denunciam a falta de serviços relacionados ao enfrentamento de violência contra a mulher quando relatam a presença do alcoolismo:

às vezes, a mulher apanha sem fazer nada. O homem está na rua com outra, vai para bebedeira e, quando chega em casa, ainda bate na mulher. (Participante do GD 3).

Uma outra questão que influencia muito a violência contra a mulher se refere a quando o homem chega bêbedo e agressivo em casa, a mulher vai em cima... Então chega o momento que ele a mata. Hoje é muito difícil. Às vezes, você conhece alguém que, no começo, demonstra ser direito e trabalhador... e depois mata a mulher por ciúmes. Eo pior de tudo é que, em nossa cidade, ainda não tem uma delegacia da mulher. Quando a gente denuncia o nosso companheiro, quem nos atende na delegacia, que são, na maioria das vezes, homens, parece que eles ficam a favor do nosso agressor, ficam sempre a favor do homem, até a maneira como eles nos fazem as perguntas sobre a agressão que sofremos. Se tivesse a Delegacia da Mulher, talvez muitas mulheres que não têm coragem de denunciar os seus companheiros poderiam fazer isso por se sentirem mais seguras conversando com outra mulher, uma policial feminina. (Participante do GD 4).

É dever do Estado e uma questão social enfrentar qualquer tipo de violência contra as mulheres. Reprimir, punir e desarraigar todas as situações de violência deve ser princípio fundamental de um país democrático que deseja uma sociedade igualitária entre mulheres e homens.

Concordamos com Meyer (2009, p. 215) ao dizer que determinados "tipos de violência se inscrevem - e se naturalizam - no âmbito de relações de poder de gênero". Para a autora, "é no contexto de relações de poder de gênero e sexualidade naturalizadas, sancionadas e legitimadas em diferentes instâncias do social e da cultura que determinadas formas de violência tornam-se possiveis" (MEYER, 2009, p. 218).

Outro aspecto que, conforme as jovens entrevistadas, pode influenciar no processo de violência nos relacionamentos diz respeito à intersecção entre a cor e o gênero. Enquanto mulheres brancas conhecem o sexismo, as negras conhecem a intersecção entre sexismo e racismo que se dirige especificamente contra elas. Há muitas consequências dessa combinação 
que as posiciona na base da pirâmide social, tendo homens brancos, mulheres brancas e homens negros acima delas.

Como afirma Carneiro (2003, p. 119),

as mulheres negras atingirem os mesmos niveis de desigualdades existentes entre homens e mulheres brancos significaria experimentar uma extraordinária mobilidade social, uma vez que os homens negros, na maioria dos indicadores sociais, encontram-se abaixo das mulheres brancas.

$\mathrm{Na}$ visão de algumas dessas jovens, "têm homens que ficam desprezando a mulher só porque ela é negra, ficam procurando outras e desprezando ela" (Participante do GD 3). Para elas, "existe esse processo de discriminação e violência por ela ser negra” (Participante do GD 3)7. Essa afirmação advém de circunstâncias que muitas dessas jovens experienciam em seu cotidiano, conforme vemos neste relato:

Eu já passei por uma situação desse tipo com o pai do meu filho; eu grávida, e era só ele ver outro rabo de saia corria atrás e ainda desfazia de mim e ficava me ameaçando. Então eu dei parte dele, e ele continuava me ameaçando. Foi aí que eu o chamei e disse: "quem cuida da casa sou eu, a mãe do seu filho sou eu. Você recebe roupa lavada, comida feita, faço tudo. O que as outras têm eu também tenho e posso te dar. Mas dessa forma eu é que não quero mais, ou você me respeita ou suma da minha frente". Hoje eu nem sei onde aquele satanás foi parar, quero ele bem longe de mim e do meu filho. Eu consegui sair da relação porque enfrentei ele, mas tem muitas mulheres que sofrem ameaças e não saem da relação. Aqui mesmo, temos colegas que apanham toda semana, são ameaçadas e não têm coragem de largar o cara, porque elas têm medo. Elas falam que, se elas prestarem queixa e a polícia pegá-lo, ele pode matá-la quando sair da cadeia, por isso que muitas não têm coragem de denunciar ou sair da relação. Quando a gente entra na relação, é tudo muito bom. (Participante do GD 3).

Segundo Souza e Daros (2006), a convivência com o medo, a dependência financeira e a submissão - até o momento em que decidem realizar a denúncia e passam por cima do sentimento de pena do marido, do tempo de vida juntos e da anulação durante o relacionamento - são alguns dos motivos que mantêm as mulheres inseridas nos contextos de relacionamentos

7 Elas são vítimas de estigmas sociais e estereótipos historicamente construídos que perduram no imaginário social desde o período do escravismo. Tratam-se de estereótipos que as hipersexualizam; estigmas como o de que as negras tudo aguentam fazem com que sejam submetidas a violências específicas, por exemplo, a obstétrica. 
violentos no Brasil. Corroborando essa ideia, uma das jovens mulheres da EJA diz:

Por isso, não podemos condenar a mulher e dizer que ela vive isso porque ela quer, ela tem é medo de morrer. A minha irmã é prova disso, o marido dela sempre batia nela, e depois ela voltava. Um certo dia, eu e a minha mãe entramos numa briga deles dois para proteger ela e os filhos, o meu irmão brigou com ele corpo a corpo, e, mesmo assim, depois ela continuou com ele. Ele já enforcou ela, e ela não teve coragem de dar parte dele. (Participante do GD 3).

Como observamos, a agressão física é um dos enfrentamentos retratados pelas jovens mulheres. Elas caracterizam a violência como um dos elementos que compõem os desafios de ser jovem mulher e aluna da EJA, conforme exposto a seguir:

Sempre corremos risco de violência e estupro para vir para a escola, pois algumas esquinas e ruas são muito escuras. Temos medo, porque já houve muitos casos aqui no bairro, inclusive com alunas aqui da escola. Mas, na maioria das vezes, umas fazem companhias às outras, principalmente, na volta para casa. (Participante do GD 1).

Como a escolarização toma parte dos projetos de vida das jovens mulheres da EJA, elas demonstram como suportam impedimentos para estarem na escola e como criam estratégias para fazerem esses enfrentamentos. É óbvio que "todas as pessoas correm riscos e podem ser vítimas de violência física, mas são as mulheres, nas relações de gênero construídas socialmente, que constantemente se veem inseguras pela violência física e, principalmente, sexual a que estamos sujeitas" (MARQUES, 2019, p. 210).

Entretanto, segundo Priscila Klein Silva (2018), se faz necessário reconhecer o lugar de fala e as experiências de cada mulher, de maneira que possamos enfrentar a desigualdade a que muitas de nós somos vulneráveis. "Não podemos buscar uma identidade aglutinadora, porém, devemos reconhecer que a vulnerabilidade à violência e à exclusão é algo bem conhecido de nós mulheres" (SILVA, P. K., 2018, p. 57). Para essa autora,

ao contarmos a nossa história, passamos por um processo que pode nos levar a nos empoderar de nós mesmas, de insurgir-nos contra as violências que marcam nossos corpos e contar nossa versão dos fatos, a versão que nos coloca mais do que vítimas, mas como sobreviventes das diversas vulnerabilidades que nos clivam por conta de 
gênero, raça e classe. $\bigcirc$ que o movimento feminista da segunda onda não percebia, mas logo o feminismo negro o fez perceber, é que não existe somente uma categoria de mulher e que ela não é exclusiva à categoria branca, classe média, com opressões e indagações típicas deste grupo. Há infinitas formas de experienciar gênero e as mulheres negras trouxeram para o centro da discussão o quanto perceber isto é importante para a luta pela igualdade. (SILVA, P. K., 2018, p. 58).

Diante da constatação, surge, em nossa opinião, a necessidade de ações concretas do Estado bem como de mudanças de comportamento, de atitudes da população diante da violência de gênero via educação (MACHADO, 1998) e de reconhecimento dos direitos da mulher, infelizmente sabemos bem como essas mudanças são lentas e das reais dificuldades em promovê-las, principalmente, quando se trata da categoria jovem, mulher, preta e pobre.

Para Araújo (2008, p. 2), a violência contra a mulher não é um fenômeno único e não acontece da mesma forma nos diferentes contextos, "ela tem aspectos semelhantes, mas também diferentes em função da singularidade dos sujeitos envolvidos". Por isso, na análise e compreensão da violência contra a mulher, é preciso que levemos em conta tanto os aspectos gerais quanto os individuais, de maneira que entendamos a diversidade do fenômeno (ARAÚJO, 2008).

A nosso ver, fazer o enfrentamento às múltiplas formas de violência contra as mulheres é uma demanda necessária em nosso país, principalmente em regiões como o Alto Sertão da Bahia. A mulher deve ser respeitada em suas especificidades além de ter garantia de acesso aos serviços de enfrentamento à violência contra ela, quando vivenciar experiências que evolvam qualquer tipo de agressão, seja ela física, moral, psicológica ou verbal.

\section{Considerações finais}

Este estudo procurou discutir e analisar o tema da violência. Teve como recorte a abordagem de gênero a partir das vozes e experiências de jovens mulheres inseridas na EJA, no Alto Sertão da Bahia.

Os resultados encontrados mostram que o índice de mulheres negras nesse segmento do ensino se sobrepõe ao de mulheres brancas e/ou amarelas, ou seja, não são quaisquer jovens mulheres que estão inseridas nessa modalidade de ensino, são jovens, mulheres, negras, sertanejas, mães, pobres. As participantes desta pesquisa vivem a experiência do trabalho 
informal, além de assumir a responsabilidade por tarefas, como cuidar da casa, dos filhos e do companheiro.

Assimetria de poder, subordinação e submissão se fazem presentes nos discursos apresentados pelas jovens mulheres da EJA; esses fatores perpassam seus contextos e suas vivências. Os discursos revelam limites e tensões que atravessam os cotidianos de jovens cerceadas por namorados, mães elou maridos. Os depoimentos das participantes da pesquisa revelam que a agressão física é um dos enfrentamentos vividos por elas, um dos elementos que compõem os desafios que é ser jovem mulher e, ao mesmo tempo, aluna da EJA. Por conta disso, denunciam a falta de serviços para combater a violência contra a mulher e apontam a presença do alcoolismo como um dos provocadores de atos violentos contra elas.

Outro marcador, apontado pelas jovens, interveniente na violência nos relacionamentos diz respeito à intersecção entre a raça e o gênero. Elas sinalizam, a partir de suas experiências, que ser negra influencia e muito na discriminação da mulher e no preconceito contra ela. Tendo isso em vista, é preciso criar políticas públicas que contemplem as especificidades das jovens mulheres sertanejas, especialmente no Alto Sertão da Bahia.

\section{Referências}

AGUIAR, J. S. Existo porque resisto: práticas de re-existência de jovens mulheres aprendizes frente às assimetrias de gênero. 2017. Dissertação (Mestrado em Educação) - Faculdade de Educação, Universidade Federal de Minas Gerais, Belo Horizonte, 2017.

ARAÚJO, J. R. Relações de gênero na educação infantil: questionamentos acerca da reduzida presença de homens e mulheres na docência. In: TEIXEIRA, A. B. M.; DUMONT, A. (org.). Discutindo relações de gênero na escola: reflexões e propostas para a ação docente. Belo Horizonte: Junqueira e Marins, 2009. p. 109-130.

ARAÚJO, M. F. Gênero e violência contra a mulher: o perigoso jogo de poder e dominação. Psicologia para América Latina, São Paulo, n. 14, 2008.

BARBOSA, A. R. As repercussões da Educação de Jovens e Adultos - EJA na vida de mulheres no município de Barra de Santana-PB. 2013. Dissertação (Mestrado em Ciências Sociais) - Universidade Federal de Campina Grande, Campina Grande, 2013. 
BARDIN, L. Análise de conteúdo. Tradução: Luís Antero Reto, Augusto Pinheiro. Lisboa: Edições 70, 1977.

BRAH, A. Diferença, diversidade, diferenciação. Cadernos Pagu, Campinas, n. 26, p. 329-376, 2006.

BRASIL. Lei $n^{0}$ 11.340, de 7 de agosto de 2006. Cria mecanismos para coibir a violência doméstica e familiar contra a mulher, nos termos do $\S 8^{\circ}$ do art. 226 da Constituição Federal, da Convenção sobre a Eliminação de Todas as Formas de Discriminação contra as Mulheres e da Convenção Interamericana para Prevenir, Punir e Erradicar a Violência contra a Mulher; dispõe sobre a criação dos Juizados da Violência Doméstica e Familiar contra a Mulher; altera o Código de Processo Penal, o Código Penal e a Lei de Execução Penal; e dá outras providências. Brasília, DF: Presidência da República, 2006. Disponivel em: https://bit.ly/31zjz9M. Acesso em: 18 mar. 2020.

CARNEIRO, S. Mulheres em movimento. Estudos Avançados, São Paulo, v. 17, n. 49, p. 117-132, 2003.

CERQUEIRA, D.; BUENO, S. (coord.). Atlas da violência. Brasilia, DF: Ipea, 2019. Disponivel em: https://bit.ly/3dODOTg. Acesso em: 18 mar. 2020.

FERREIRA, A. T. B. Ler e escrever também é uma questão de gênero. In: LEAL, T. F.; ALBUQUERQUE, E. B. C. (org.). Desafios da Educação de Jovens e Adultos: construindo práticas de alfabetização. Belo Horizonte: Autêntica, 2007. p. 71-88.

LEONCY, C. E. T. Mulheres na EJA: questões de identidade e gênero. 2013. Dissertação (Mestrado em Educação) - Faculdade de Educação, Universidade Estadual de Campinas, Campinas, 2013.

MACHADO, L. Z. Matar e morrer no feminino e no masculino. In: OLIVEIRA, D. D.; LIMA, R. B.; GERALDES, E. C. G. (org.). Primavera já partiu: retratos de homicídios femininos no Brasil. Petrópolis: Vozes, 1998. p. 1-20.

MARQUES, T. G. Um pé na roça - outro na Universidade: experiências de acesso e permanência de jovens mulheres da roça na Universidade do Estado da Bahia (UNEB). 2019. Tese (Doutorado em Educação) - Faculdade de Educação, Universidade Federal de Minas Gerais, Belo Horizonte, 2019. 
MATOS, M. Teorias de gênero ou teorias e gênero? Se e como os estudos de gênero e feministas se transformaram em um campo novo para as ciências. Estudos Feministas, Florianópolis, v. 16, n. 2, p. 333-357, 2008.

MENEZES, C. S. A participação feminina em turmas da educação de jovens e adultos. In: COLÓQUIO INTERNACIONAL PAULO FREIRE, 5., 2005, Recife. Anais [...]. Recife: UFPE, 2005. Disponivel em: https://bit.ly/2BXU4nJ. Acesso em: 10 dez. 2017.

MEYER, D. Corpo, violência e educação: uma abordagem de gênero. In: JUNQUEIRA, R. D. (org.). Diversidade sexual na educação: problematizações sobre a homofobia nas escolas. Brasilia, DRF: Unesco, 2009. p. 213-242.

NARVAZ, M. G.; SANT'ANNA, S. M. L.; TESSELER, F. A. Gênero e educação de jovens e adultos: a histórica exclusão das mulheres dos espaços de saber-poder. Diálogo, Canoas, n. 23, p. 93-104, 2013.

REIS, S. M. A. O. Mulheres camponesas e culturas do escrito: trajetórias de lideranças comunitárias construídas nas CEBS. 2014. Tese (Doutorado em Educação) - Faculdade de Educação, Universidade Federal de Minas Gerais, Belo Horizonte, 2014.

SCOTT, J. W. Gênero: uma categoria útil de análise histórica. Educação e Realidade, Porto Alegre, v. 20, n. 2, p. 71-99, 1995.

SILVA, M. A. Trajetórias de mulheres negras ativistas. Curitiba: Appris, 2017.

SILVA, P. A. Gênero, Raça, Classe e Letramento: a resistência de jovens mulheres por meio da fala e da escrita. 2018. Tese (Doutorado em Letras e Linguística) Faculdade de Letras, Universidade Federal de Goiás, Goiânia, 2018.

SILVA, P. K. Registros de um sonho: jovens mulheres privadas de liberdade fotografando seus projetos de vida. 2018. Dissertação (Mestrado em Educação) - Escola de Humanidades, Pontifícia Universidade Católica do Rio Grande do Sul, Porto Alegre, 2018.

SILVA, S. G. Preconceito e discriminação: as bases da violência contra a mulher. Psicologia: Ciência e Profissão, Brasilia, DF, v. 30, n. 3, p. 556-571, 2010. 
SOUZA, N. P. M. M. Mulheres da EJA: entre sonhos e desafios da continuidade na escolarização de alunas da rede municipal de Seropédica-RJ. 2015. Dissertação (Mestrado em Educação, Contextos Contemporâneos e Demandas Populares) - Instituto de Educação, Instituto Multidisciplinar, Universidade Federal Rural do Rio de Janeiro, Seropédica, 2015.

SOUZA, P. A; DAROS, M. A. Os motivos que mantêm as mulheres vitimas de violência no relacionamento violento. Revista de Ciências Humanas, Florianópolis, n. 40, p. 509-527, 2006.

UNESCO. Declaração mundial sobre educação para todos: satisfação das necessidades básicas de aprendizagem. Jomtien: Unesco, 1990. Disponivel em: https://bit.ly/31xiYFy. Acesso em: 28 jan. 2017.

Recebido em março de 2020.

Aprovado em junho de 2020. 